\title{
Potential Heart Problems in Convalescent COVID-19 Children: Alert from a Cuban Study
}

\author{
Lisset Ley-Vega MD MS
}

COVID-19, the disease caused by the novel coronavirus SARS-CoV-2, is present in more than 200 countries and regions and is having a devastating impact worldwide. The sheer number of critical and convalescent patients-including pediatric patientsrepresents a challenge to the global medical community.

Although children with COVID-19 are often asymptomatic or exhibit only mild symptoms, they can transmit the disease and suffer from serious manifestations. In Cuba, 2932 patients $\leq 18$ years old tested positive for COVID-19 between March 2020 and February 1, 2021. Most of these children presented few to no symptoms upon diagnosis. At the time of this writing, $82.8 \%$ of those children had recovered,[1] and there had not been a single pediatric death due to the novel coronavirus.

Nevertheless, the world has seen a significant uptick in pediatric infections linked to outbreaks following easing of restrictions designed to control transmission. Cuba is no exception: the island registered 1624 pediatric cases in a single post-holiday month (January 2021) after opening for visitors.[1]

Cuba's COVID-19 Prevention and Control Plan applies national, multidisciplinary and intersectoral protocols to all COVID-19 patients.[2] These define care for suspected, confirmed and convalescent cases, including in pediatric ages. The therapeutic and management protocols for Cubans $\leq 18$ years old according to national case classifications (all medications are produced in Cuba) are contained in the box below.

Pediatric COVID-19 patients tend to evolve more favorably than adults. While individual immune response depends on virus exposure and other factors unique to each patient, a child's immune system differs from an adult's - specifically in the angiotensin-converting enzyme 2 (ACE2), the functional receptor for SARS-CoV-2 to enter into human cells. Children also have fewer comorbidities like hypertension, cardiovascular disease and diabetes mellitus than adults.[3]

One area of growing research interest is cardiovascular damage in children and adolescents recovering from COVID-19. Recent studies indicate that long-term cardiovascular complications from SARS-CoV-2 infection may include arrhythmias, myocarditis, pericarditis, shock, multisystem inflammatory syndrome (MIS) similar to Kawasaki disease, as well as stress-induced cardiomyopathy (Takotsubo syndrome) and sudden death.[3]

Viral infection can damage heart cells in both early and late stages of infection by inducing direct myocardial damage, hyper-inflammation and an immune response causing systemic inflammation and cytokine storm-especially Interleukin-6 that directly affects the QT interval. Other relevant factors may include: vasculitis, vascular microthrombosis, disseminated intravascular coagulation, hypoxia, electrolyte imbalances, myocardial ischemia and ACE2-deficiency disorder-as ACE2 protein expression occurs in various tissues, including heart and lung, with consequences for ion channel function.[4]

Preliminary studies demonstrate myocardial inflammation and injury (without serious symptoms) in recovering COVID-19 patients two months after diagnosis.[5] Although we know that COVID-19 affects both the respiratory system and cardiovascular function over time, the actual prevalence of persistent COVID-19 heart problems is unknown. Furthermore, cardiovascular damage linked to COVID-19 is likely underreported due to low autopsy rates and suspected multi-organ failure based on clinical and radiology exams rather than systematic use of electrocardiograms, echocardiograms, Holter monitors and other measurements. Cardiovascular damage may also go under-detected as a result of low symptomology and insufficient research about subacute (5-20 days after symptom onset), mediumand long-term sequelae of the disease.[4,5] Researchers need more time to study the long-term cardiovascular manifestations of COVID-19, especially in mild pediatric cases.

In 2020, Cuba launched a nationwide study coordinated by the National Genetics Center and carried out by the National

\begin{tabular}{|c|c|c|}
\hline Case classification & Remitted to & Treatment \\
\hline Contact of confirmed case & Isolation center & PrevengHo-Vir (homeopathic) \\
\hline Suspected - mild symptoms & Hospital & Oseltamivir/Azithromycin; PrevengHo-Vir \\
\hline $\begin{array}{l}\text { Confirmed - PCR-positive, asymptomatic or mild } \\
\text { symptoms w/o risk factors }\end{array}$ & Hospital & Interferon alfa-2b \\
\hline $\begin{array}{l}\text { Confirmed - PCR-positive, mild symptoms with risk } \\
\text { factors }\end{array}$ & Hospital & Interferon alfa-2b; Lopinavir; Ritonavir \\
\hline $\begin{array}{l}\text { Confirmed - PCR-positive, moderate symptoms without } \\
\text { risk factors }\end{array}$ & Hospital & $\begin{array}{l}\text { Lopinavir; Ritonavir; Biomodulina T } \\
\text { (immunomodulator) }\end{array}$ \\
\hline $\begin{array}{l}\text { Confirmed - PCR-positive, moderate symptoms with risk } \\
\text { factors, or severe symptoms }\end{array}$ & Hospital & $\begin{array}{l}\text { Steroids; anti-coagulatants; Jusvinza (CIGB 258), } \\
\text { used only in those >10 years old }\end{array}$ \\
\hline Critical & Hospital & $\begin{array}{l}\text { Steroids; anti-coagulants; Jusvinza (CIGB 258); anti- } \\
\text { biotics (sepsis/septic shock); assisted ventilation as } \\
\text { needed. Individualized, according to clinical status }\end{array}$ \\
\hline Convalescent - PCR-negative for 14 days & Home & $\begin{array}{l}\text { Comprehensive follow-up in local health area by } \\
\text { primary healthcare teams }\end{array}$ \\
\hline
\end{tabular}




\section{Researchers need more time to study the long- term cardiovascular manifestations of COVID-19, especially in mild pediatric cases}

Genetics Network entitled, Genetic risk factors associated with COVID-19 clinical severity in Cuban patients and their first-degree relatives. Our study, Clinical, epidemiological and cardiovascular factors in COVID-19 convalescent patients 18 years and under, is part of this broader study and was conducted at the children's heart service of the José Luis Miranda Provincial Pediatric University Hospital (Santa Clara, Villa Clara Province).

We studied 110 COVID-19 convalescent patients $\leq 18$ years old, during Cuba's first three epidemiological stages for the disease (March-June 2020; July-October 2020; and November 2020February 2021). Using retrospective medical interviews to identify antecedents and collect other relevant disease data (symptoms, treatment, length of hospitalization and more), we found all the youngsters participating in the study were asymptomatic or had mild symptoms upon diagnosis. Additionally, they were in good nutritional health and as a group, had a low rate of chronic disease.

We began to actively identify cardiac issues among these convalescent patients using, among others, epidemiological and clinical criteria, electrocardiograms, echocardiograms and chest X-rays. We based our surveillance for cardiac anomalies on a clinical method evaluating mild symptoms that included fatigue after age-appropriate physical activity similar to post-COVID-19 infection asthenia (physical weakness or lack of energy); chest pain; and cardiac rhythm abnormalities. These were complemented by heart rate and blood pressure measurements.

We found cardiovascular abnormalities in 20 patients (18.1\%) including myocarditis, pericarditis, arrhythmias and hypertension. These patients evolved satisfactorily following several weeks of monitoring and treatment, after which they received monthly follow-up.

Pediatric COVID-19 patients with heart abnormalities are treated according to national cardiology protocols established for children with congenital and acquired heart problems. This treatment is individualized for each child with or recovering from COVID-19 and approved by a multi-disciplinary team comprised of cardiologists, immunologists, pulmonologists, nephrologists, neurologists and psychiatrists. In our center we have used diuretics, vasodilators, non-steroidal anti-inflammatories (NSAIDs), beta-blockers and immunomodulators to treat pediatric cardiovascular patients, with good results.
Myocardial, pericardial, electrocardiographic and vascular abnormalities are potentially reversible in children recovering from COVID-19. In our opinion, standardizing early detection and timely treatment for these patients can improve their prognosis-however reserved. We continue actively searching for cardiovascular abnormalities in COVID-19 pediatric cases using the methodology described as part of our strategy to minimize the medium- and long-term impact of the pandemic and post-infection complications among children.

It is both urgent and imperative that we continue conducting research about SARS-CoV-2 throughout every stage of the disease, from transmission to recovery and beyond. We recommend cardiovascular studies specifically for convalescent children, based on current evidence and using the latest technology. A cardiology focus should be integrated into the support and follow-up for pediatric patients, monitoring closely for subclinical abnormalities and hidden comorbidities. -1 -

\section{REFERENCES}

1. Ministerio de Salud Pública. República de Cuba. CATEGORIA: COVID 19. [Internet] . Havana: Ministry of Public Health (CU); 2021 Feb [cited 2021 Feb 17]. Available at: https://salud.msp.gob.cu/category/covid-19/?doing_wp_cron $=1618148407.5727219581604003906250$. Spanish.

2. Ministerio de Salud Pública. República de Cuba. Protocolo de actuación nacional para la Covid-19: versión 1.6 [Internet]. Havana: Ministry of Public Health (CU); 2021 Feb [cited 2021 Feb 17]. Available at: https://salud.msp.gob.cu/ protocolo-de-manejo-clinico-de-covid-19-version-1-6/. Spanish.

3. Clínica Mayo [Internet]. Rochester: Clínica Mayo; c2020. COVID-19 (coronavirus en bebés y niños); [cited 2020 Aug 30]; [about 6 p.]. Available at: https:// www.mayoclinic.org/es-es/diseases-conditions/coronavirus/in-depth/coronavi rus-in-babies-and-children/art-20484405. Spanish.

4. Sociedad Venezolana de Cardiología [Internet]. Caracas: Sociedad Venezolana de Cardiología; c2021. Especiales. COVID-19 en Cardiología Pediátrica y Cardiopatía Congénita; 2020 May 2 [cited 2020 Sep 21]; [about 8 p.]. Available at: https://svcardiologia.org/es/especiales/coronavirus/493-covid-19-cardiolo gia-pediatrica-congenita.html. Spanish.

5. Folgarait A. ¿Existe el síndrome post COVID-19? [Internet]. Buenos Aires: Sociedad Argentina de Cardiología; 2020 Aug 19 [cited 2020 Aug 20]. Available at: https://www.sac.org.ar/actualidad/existe-el-sindrome-post-covid-19/

\section{THE AUTHOR}

Lisset Ley-Vega (lissetlv@infomed.sld.cu), physician with dual specialties in pediatrics and cardiology, and a master's degree in comprehensive children's health. Associate professor and associate researcher, cardiology service, José Luis Miranda Provincial Pediatric University Hospital, Santa Clara, Villa Clara, Cuba. https://orcid.org/0000-0001-8159-2930

Submitted: March 1, 2021

Approved for publication: April 8, 2021

Disclosures: None 